\title{
POLÍTICA NA FORMA DA LEI: 0 ESPAÇO DOS CONSTITUCIONALISTAS NO BRASIL DEMOCRÁTICO*
}

Fabiano Engelmann e

Luciana Penna

Um dos fundamentos principais da autonomização do campo jurídico, em relação a outras modalidades de poder político, é a formação de sentidos comuns acerca das "causas políticas" postas na forma jurídica. Os consensos e também os dissensos em torno das possibilidades com que determinados temas podem e devem ser tratados contribuem para a delimitação do "universo das soluções propriamente jurídicas" que, conforme aponta Bourdieu (1986) é um dos fundamentos da força do direito.

As doutrinas jurídicas - conjunto de conhecimentos eruditos que estão na base dos argumentos de autoridade dos juristas - são difundidas através da edição de obras, individuais ou coletivas, assinadas por especialistas dotados de legitimidade acadêmica, e contribuem para a formação dos sentidos compartilhados entre os juristas sobre o processo político e a execução das políticas públicas.

\footnotetext{
* Texto resultante de pesquisa apoiada pelo CNPq, projeto Intérpretes da Constituição, porta-vozes de políticas: juristas e ordem política brasileira (1990-2010).
} 
Este artigo tem como um de seus principais objetivos enfatizar a importância de estudar o espaço da produção das doutrinas constitucionais brasileiras contemporâneas. Em especial, a imbricação do debate jurídico com a conjuntura das lutas políticas desencadeadas já na Constituinte de 1986 e prolongadas nas batalhas de sentido dos marcos institucionais da Constituição de 1988. Uma das dimensões mais visíveis do fenômeno é a emergência dos "constitucionalistas", categoria de agentes encarregada de produzir e difundir a interpretação do sentido da regra constitucional. A progressiva consolidação institucional do regime democrático brasileiro, ao longo das décadas de 1990 e 2000, tem nessa categoria de "intelectuais da Constituição" uma ancoragem muito forte para a legitimação de concepções jurídicas da vida pública.

Enfocar a emergência dessa categoria não implica desconsiderar todo o conjunto de agentes que participa do 178 debate político em torno de princípios constitucionais que abrange uma larga "comunidade de intérpretes", a qual inclui jornalistas, cientistas sociais, lideranças de movimentos sindicais e associativos, entre outros atores. A questão essencial que pretendemos propor aqui é que, em maior ou menor grau, o debate constitucional é fortemente agendado por aqueles que detêm o monopólio de dizer o direito. E isso perpassa ao mesmo tempo as diferentes competências de Estado das várias categorias de instituições judiciais (Poder Judiciário, Ministério Público, Defensoria Pública, Advocacia de causas coletivas, procuradorias de diversos ramos da administração pública) e a luta intelectual que ocorre entre os constitucionalistas.

A "supremacia da Constituição" construída nos embates em torno do sentido das suas regras é um processo que varia em diferentes conjunturas. Em um primeiro momento que circunda a Assembleia Constituinte, entra em jogo o potencial de intervenção, de mudança social que a regra 
constitucional pode proporcionar. Posteriormente, nas décadas de 1990 e 2000, por intermédio das diversas categorias de juristas ou de movimentos sociais, o ativismo constitucional assume diferenciadas modalidades, avançando para uma crescente mise en forme do processo político e da execução de políticas. Embora os efeitos desse processo se façam sentir principalmente pela ação dos juristas que detêm o poder jurisdicional e propositivo de ações judiciais, a base está na formação da doxa derivada da força do texto construído e reconstruído permanentemente por seus doutrinadores autorizados, os constitucionalistas.

\section{Para uma análise sociopolítica das doutrinas constitucionais}

[...] os leitores serão levados a pensar que se uma legislação foi descrita de um ponto de vista jurídico, pelos juristas profissionais, então esta legislação não é somente a expressão de uma relação de forças passageira, mas que ela é "o direito", dito de outro modo, que ela é da natureza das coisas, normal, justa.

(Troper, 1993, P. 92)

Abordar a produção intelectual dos profissionais do direito do ponto de vista das ciências sociais tem como pressuposto evitar a representação ideológica que os juristas constroem a seu respeito. Em especial, deve-se refutar a ideia de que o debate doutrinário é um debate "técnico", objeto de especialistas e autônomo em relação às polarizações políticas. Desse modo, seguindo Dezalay (1989, p. 232), pode-se afirmar que compreender a produção doutrinal implica romper com a ideia de que ela se constitui em uma "construção científica tendo por fim o aperfeiçoamento do direito fora dos constrangimentos sociais" .

${ }^{1}$ Todas as traduções foram realizadas pelos autores especialmente para este artigo. 
Em sentido geral, os processos de adoção de novas Constituições e a consequente (re)ordenação da vida política são elementos que favorecem a formalização de representações sobre o funcionamento do Estado. Nesse contexto, os intérpretes do sentido da nova "forma do Estado" assumem um papel de destaque. Poirmeur (1993), ao estudar as causas da recente ascensão do constitucionalismo na França, aponta as mudanças no papel do direito constitucional ao longo da segunda metade do século XX. No final da IV República, em 1956, há um declínio da ideia de supremacia da Constituição, e, após, com o governo De Gaulle, a interpretação da Constituição restou completamente centralizada na Presidência. Conforme o autor, somente a partir dos anos 1970, com as transformações da conjuntura ideológica e política que implicaram uma reordenação das relações de força no campo intelectual, o constitucionalismo ganharia influência política, o que foi representado pelos liberais franceses, como 180 "a vitória do direito sobre a política" (Poirmeur, 1993, p. 15).

No mesmo sentido, Lacroix (1992), ao estudar o debate em torno da legitimidade de atos da presidência da república francesa em 1986, ressalta a entrada em cena dos constitucionalistas, que tendem a posicionar a "regra de direito" como princípio de explicação do comportamento dos atores políticos. Conforme Lacroix, os constitucionalistas legitimam sua expertise ao partilharem e propagarem a ilusio da "adequação" do jogo político às regras e não o contrário: o uso e a construção do sentido das regras no curso das batalhas políticas.

Assim, se tem a transformação do debate sobre questões políticas em um debate entre especialistas sobre a forma na qual se devem adequar os atores quando abordam questões públicas. No entanto, a crescente imposição, como evidente, do saber disciplinar e doutrinário do direito constitucional encarnando o "sentido correto" da atividade política dificulta a compreensão do papel exercido por essa espécie de saber erudito no jogo político. Para melhor análise da 
legitimação das doutrinas constitucionais e dos seus especialistas no espaço público, Lacroix (1992) propõe estudar os autores da formalização jurídica e não apenas a análise das ideias do direito constitucional em abstrato.

Se tomarmos o caso brasileiro, constatamos que, desde o Império, os juristas estiveram posicionados como intérpretes legítimos das instituições políticas. Em um primeiro momento, pelos estudos feitos na Universidade de Coimbra e posterior ocupação de postos de poder na administração imperial ${ }^{2}$ e, a partir de 1827, pela formação nas academias de São Paulo e Olinda, estendida, com a proclamação da República, para as demais províncias brasileiras (Venâncio Filho, 1977).

No entanto, o fraco desenvolvimento da carreira acadêmica como atividade profissional é um fator relevante que distingue a intervenção dos brasileiros em relação a outros contextos, como a França e a Alemanha (Bourdieu, 1986; Sacriste, 2011). Isso porque, nesses casos, o professor de direito intervém, desde o final do século XIX, de um "lugar neutro", ancorado no "poder acadêmico". No Brasil, a recente expansão da carreira de professor de direito e as possibilidades de reconversão do conhecimento elaborado nos cursos de pós-graduação segue o ritmo da recomposição das instituições políticas e judiciais. Desse modo, a diversidade das problemáticas traduzidas para o espaço jurídico e o papel de mediação exercido pelas instituições daí decorrentes repercutem na demanda por novas expertises sobre o Estado e a Constituição. Nesse cenário, se destaca o direito constitucional, linguagem privilegiada da formalização legal das políticas de Estado.

\footnotetext{
2 As escolas de direito criadas no Brasil a partir do modelo de Coimbra, assim como as práticas políticas dos bacharéis em direito se constituíram em um saber-fazer político específico - o bacharelismo -, baseado na retórica, na conciliação política e na importação de modelos europeus, conforme indicam os estudos de Adorno (1988) e Carvalho (1996). Sobre a organização da magistratura no Império, ver Koerner (1998).
} 
Os porta-vozes do sentido da Constituição não aparecem ancorados apenas nas universidades e nas profissões jurídicas, mas circulam em diversos espaços públicos, desde associações de constitucionalistas, consultoria a governos, membros de comissões legislativas até a ocupação de postos políticos. A legitimidade dos constitucionalistas no espaço do poder não é dada apenas por sua expertise intelectual, a ela se agrega um conjunto de condicionantes presentes em seus trajetos profissionais e políticos, que os vinculam às diferentes tomadas de posição no debate sobre o sentido das regras constitucionais que variam conjunturalmente.

\section{Intérpretes e doutrinas constitucionais no Brasil: apostas políticas e acadêmicas}

No Brasil, o espaço da produção das doutrinas jurídicas não se constitui - como no caso francês e alemão ${ }^{3}$ - em um cam-

182 po relativamente autônomo formado por juristas de perfil acadêmico que disputam a legitimidade de seus produtos com os praticantes do direito. Dito de outro modo, não se verifica uma divisão radical entre o "mundo dos teóricos" e o "mundo dos práticos". Assim, mesmo com a grande expansão do ensino jurídico de pós-graduação a partir da segunda metade da década de 1990, a legitimidade dos bens simbólicos em forma de produção intelectual é estreitamente condicionada à relação desses agentes com o universo dos práticos.

No entanto, a profusão de dissertações e teses, bem como a expansão da população de docentes com título de doutorado e dedicação exclusiva são indicativos importantes de que a profissionalização da produção doutrinal acompanhou o processo de retorno dos juristas ao espaço

\footnotetext{
${ }^{3}$ Para maior detalhamento sobre a configuração da produção doutrinal e as oposições entre "professores de direito - doutrinadores" e "práticos" na França e Alemanha, ver Chevalier (1993) e Bourdieu (1986).
} 
público. O segundo momento da expansão do campo jurídico evidenciou as diversas formas de ativismo em torno da "efetivação" dos marcos institucionais possibilitados pela Constituição de $1988^{4}$.

A análise dos livros e artigos de doutrina que abordam a "judicialização de políticas" (cf. Engelmann e Cunha Filho, 2013) - produção intelectual posicionada no âmbito disciplinar do direito constitucional - é um caso bastante representativo do fenômeno. A mediação do Poder Judiciário na agenda de políticas envolve um jogo em que o centro é a disputa pelo sentido das normas e princípios que regram as políticas de governo nas mais diferentes esferas. O espaço da formação dos argumentos nas doutrinas judiciais atrelado às confrontações presentes no campo das práticas é permeado por diversas oposições que discutem a juridicidade de tomadas de decisão governamentais.

Dessa forma, a análise da trajetória de um grupo de constitucionalistas brasileiros, cuja produção tem tido repercussão nas últimas décadas é um dos caminhos para se obter uma percepção mais abrangente dos atributos políticos dos intérpretes das normas. Em grande medida, o debate das doutrinas acerca do sentido da Constituição de 1988 é pautado por uma geração graduada em direito nas décadas de 1950 e 1960, cuja produção intelectual adquire grande visibilidade no contexto da Constituinte de 1986. A emergência no espaço público desse grupo ocorre principalmente com a publicação de obras sobre o "modelo ideal" de Constituição ${ }^{5}$. Também advém de sua participação nas diversas comissões de notáveis que circundam o debate da Assembleia Constituinte, entre as quais a Comissão de Estudos Constitucionais no Congresso Nacional.

\footnotetext{
${ }^{4}$ Sobre a expansão dos programas de pós-graduação em direito e a produção de doutrinas jurídicas, ver Engelmann (2006a, 2008).

${ }^{5}$ Como, por exemplo, o livro Constituição e constituinte, de Dalmo de Abreu Dallari, lançado em 1982 pela editora Saraiva.
} 
As modalidades de intervenção pública ocorrem nesse cenário valendo-se de uma expertise constitucional que inclui a proposição de modelos, anteprojetos e justificativas para a adoção de sistemas jurídico-políticos. Como exemplo, podem-se citar o Anteprojeto da Constituição, elaborado por José Afonso da Silva (cf. Cittadino, 2000), e a publicação de livros, como o de Ives Gandra da Silva Martins, em 1987, intitulado Roteiro para uma Constituição - acompanhado de dois textos de anteprojeto e justificação da ordem econômica e social e do sistema tributário ${ }^{6}$, e o livro Ideias para a Nova Constituição brasileira, de Manoel Gonçalves Ferreira Filho, também publicado em 1987.

Da mesma maneira, a intervenção dos juristas na produção da nova Constituição contribui para a promoção da disciplina de direito constitucional. A elaboração das doutrinas a partir do processo da Constituinte aparece como a (re)fundação de heranças teóricas repetidas por décadas 184 em manuais de direito, sucessivamente reeditados, combinadas com a importação de vertentes estrangeiras recentes. O prestígio nacional alcançado no meio editorial é reforçado no final da década de 1980, quando se vincula à construção da posição de intérprete legítimo da nova ordem jurídico-política.

O enquadramento político-ideológico dos constitucionalistas brasileiros no contexto da abertura política dos anos 1980 foi abordado por Gisele Cittadino (2000) ao tratar da filosofia constitucional contemporânea. A autora demonstra que os juristas reunidos em torno da Constituinte refletiram uma divergência, que tomou a forma de debate sobre o modelo e o conteúdo da futura Constituição, tornando visível posicionamentos em disputa entre os "comunitaristas" e os "liberais" (Cittadino, 2000, p. 15). São identificados

\footnotetext{
${ }^{6}$ Publicado pela editora Forense junto com a Academia Internacional de Direito Econômico e Economia.
} 
dois grupos. O primeiro, composto pelos defensores de um modelo de Constituição "dirigente", "democrático-social”, "programática", comprometida com a adoção do Estado do bem-estar social, do qual fazem parte o autor do anteprojeto, o constitucionalista José Afonso da Silva, além de Paulo Bonavides, Dalmo de Abreu Dallari, Fabio Konder Comparatto, Carlos Roberto de Siqueira Castro e Joaquim de Arruda Falcão Neto (Cittadino, 2000, p. 14). Já o segundo reunia empresários e juristas designados pela imprensa da época como "conservador", formado por "ideólogos de direita", críticos do modelo "social" de Constituição, no qual se situam os juristas Ney Prado, Miguel Reale e Gilberto Ulhôa Canto (Cittadino, 2000, p. 33).

O debate com pretensões científicas dos doutrinadores dos anos 1990, centrado mais especificamente sobre a "aplicabilidade das normas constitucionais", pode ser apreendido como um desdobramento dessa disputa política mais aberta ao longo do processo constituinte.

\section{Constitucionalistas e batalhas em torno da "aplicabilidade da Constituição de 1988"}

Um dos pontos de partida importantes para a análise da construção do espaço dos produtores de doutrinas no Brasil é o mapeamento dos manuais de direito constitucional mais consagrados entre os juristas. Tais obras são publicadas por editoras especializadas em livros jurídicos e voltadas para o ensino universitário massificado. As informações editoriais sobre os livros apontam que a maioria é publicada sucessivamente desde a década de 1970, concorrendo com obras mais recentes. Os autores reeditados compõem um pequeno grupo que ocupa postos de consultoria e cargos públicos no âmbito de comissões, além de aparecerem como fundadores de associações de constitucionalistas (ver Quadro 1).

As editoras Malheiros e Saraiva concentram a maioria das publicações. A Malheiros, especializada em livros jurídicos, 
publica os três manuais de direito constitucional com maior número de edições, de Celso Ribeiro Bastos, Paulo Bonavides e José Afonso da Silva, todos intitulados Curso de direito constitucional. Um dos eixos que opõe os escritores de manuais com repercussão nas décadas de 1990 e 2000 é o debate em torno da "aplicabilidade da Constituição", que remete à controvérsia sobre a capacidade dos arcabouços normativos de gerar políticas públicas através da mobilização do Judiciário para efetivação de direitos. No polo de juristas que se posicionam contrários "à plena aplicação das normas constitucionais”, destaca-se Manoel Gonçalves Ferreira Filho, professor da Universidade de São Paulo. O constitucionalista assume posições públicas questionando a possibilidade de efetivar as normas "progressistas"; Ferreira Filho teve passagem por cargos políticos de destaque nacional (ver Quadro 2).

Refletindo sobre seu posicionamento "crítico" ao modelo 186 adotado em 1988, Ferreira Filho argumenta, em entrevista publicada em 2005, sobre os "efeitos perversos" gerados pela Constituição de 1988, com destaque para a "concentração de poder nas mãos do Executivo", a "proliferação dos partidos”, a "politização do Judiciário", a "centralização na federação" e a "proliferação de municípios". Conforme Ferreira Filho (2005b, p. 32):

Deflui deste balanço que se procurou fazer com prudência, um juízo mitigado da Constituição de 1988. Se tem ela méritos importantes - a implantação da democracia, da liberdade política, do espírito de cidadania, de apego aos direitos fundamentais - isto não ocorreu sem deméritos graves - a concentração do Poder em mãos do Executivo, a fragilização do Legislativo, a pulverização do sistema partidário, a politização do Judiciário, a centralização do federalismo, a proliferação municipalista, afora o seu estatismo e o seu assistencialismo corporativista. 


\section{Quadro 1}

Autores de manuais de direito constitucional com maior circulação no Brasil

\begin{tabular}{|c|c|c|c|c|}
\hline Autor/posição & Livro (título) & $\begin{array}{l}\text { Ano da } \\
\text { primeira } \\
\text { edição }\end{array}$ & $\begin{array}{c}\text { Edição } \\
\text { em } \\
2012\end{array}$ & Editora \\
\hline $\begin{array}{l}\left.1^{\circ}\right) \text { Manoel } \\
\text { Gonçalves } \\
\text { Ferreira Filho }\end{array}$ & Curso de direito constitucional & 1967 & $36^{\mathrm{a}}$ & Saraiva \\
\hline $\begin{array}{l}\left.2^{\circ}\right) \text { José Afonso } \\
\text { da Silva }\end{array}$ & Curso de direito constitucional & 1976 & $35^{\mathrm{a}}$ & $\begin{array}{l}\text { Malheiros } \\
\text { Editores }\end{array}$ \\
\hline $\begin{array}{l}\left.3^{\circ}\right) \text { Dalmo de } \\
\text { Abreu Dallari }\end{array}$ & $\begin{array}{c}\text { Elementos de teoria geral do } \\
\text { Estado }\end{array}$ & 1971 & $31^{\mathrm{a}}$ & Saraiva \\
\hline $\begin{array}{c}\left.4^{\circ}\right) \text { Roque } \\
\text { Antonio Carraza }\end{array}$ & $\begin{array}{c}\text { Curso de direito constitucional } \\
\text { tributário }\end{array}$ & 1991 & $27^{\mathrm{a}}$ & $\begin{array}{c}\text { Revista dos } \\
\text { Tribunais/ } \\
\text { Malheiros }\end{array}$ \\
\hline $\begin{array}{l}\left.5^{\circ}\right) \text { Paulo } \\
\text { Bonavides }\end{array}$ & Curso de direito constitucional & 1982 & $25^{\mathrm{a}}$ & $\begin{array}{l}\text { Malheiros } \\
\text { Editores }\end{array}$ \\
\hline $\left.6^{\circ}\right)$ Michel Temer & $\begin{array}{l}\text { Elementos de direito } \\
\text { constitucional }\end{array}$ & 1987 & $24^{a}$ & $\begin{array}{l}\text { Malheiros } \\
\text { Editores }\end{array}$ \\
\hline $\begin{array}{l}7^{\circ} \text { ) Celso Ribeiro } \\
\text { Bastos }\end{array}$ & Curso de direito constitucional & 1967 & $22^{\mathrm{a}}$ & $\begin{array}{l}\text { Malheiros } \\
\text { Editores }\end{array}$ \\
\hline $\begin{array}{l}\left.8^{\circ}\right) \text { Vidal Serrano } \\
\text { Nunes Júnior } \\
\text { e Luiz Alberto } \\
\text { David Araújo }\end{array}$ & Curso de direito constitucional & 1998 & $16^{\mathrm{a}}$ & $\begin{array}{l}\text { Saraiva/ } \\
\text { Verbatim }\end{array}$ \\
\hline $\begin{array}{l}\left.9^{\circ}\right) \text { Flávia } \\
\text { Piovesan }\end{array}$ & $\begin{array}{l}\text { Os direitos humanos e o direito } \\
\text { constitucional internacional }\end{array}$ & 1996 & $13^{\mathrm{a}}$ & $\begin{array}{l}\text { Max Limonad/ } \\
\text { Saraiva }\end{array}$ \\
\hline $\begin{array}{c}\left.10^{\circ}\right) \text { André } \\
\text { Ramos Tavares }\end{array}$ & Curso de direito constitucional & 2002 & $10^{\mathrm{a}}$ & Saraiva \\
\hline $\begin{array}{l}\left.11^{\circ}\right) \text { Gilmar } \\
\text { Ferreira Mendes }\end{array}$ & Curso de direito constitucional & 2008 & $6^{\mathrm{a}}$ & Saraiva \\
\hline $\begin{array}{c}\left.12^{\circ}\right) \text { Luis } \\
\text { Roberto Barroso }\end{array}$ & $\begin{array}{l}\text { Interpretação e aplicação da } \\
\text { Constituição }\end{array}$ & 1996 & $7^{\mathrm{a}}$ & Saraiva \\
\hline $\begin{array}{l}\left.13^{\circ}\right) \text { Ives Gandra } \\
\text { da Silva Martins }\end{array}$ & $\begin{array}{l}\text { Comentários à Constituição } \\
\text { do Brasil: promulgada em } 5 \text { de } \\
\text { outubro de } 1988 \text { (9 volumes } \\
\text { divididos em diversos tomos) }\end{array}$ & 1988 & $3^{\mathrm{a}}$ & Saraiva \\
\hline Ney Prado & $\begin{array}{l}\text { Razões das virtudes e vícios da } \\
\text { Constituição de 1988: subsídios } \\
\text { à revisão constitucional }\end{array}$ & 1994 & $3^{\mathrm{a}}$ & $\begin{array}{l}\text { Editora } \\
\text { Forense }\end{array}$ \\
\hline
\end{tabular}

Fonte: Base de dados do projeto de pesquisa Intérpretes da Constituição, Porta-Vozes de Políticas: juristas e ordem política brasileira (1990-2010). 


\section{Quadro 2}

Trajeto político e acadêmico de Manoel Gonçalves Ferreira Filho

\begin{tabular}{|c|c|c|}
\hline $\begin{array}{l}\text { Titulação } \\
\text { acadêmica }\end{array}$ & $\begin{array}{l}\text { Local de } \\
\text { inserção } \\
\text { docente }\end{array}$ & Postos políticos ocupados e período \\
\hline $\begin{array}{c}\text { Graduado pela } \\
\text { USP em } 1957 . \\
\text { Doutor em } \\
\text { direito pela } \\
\text { Universidade } \\
\text { de Paris, } 1960 . \\
\text { Livre-docente } \\
\text { pela USP em } \\
1965 . \\
\text { Editora pela } \\
\text { qual publica: } \\
\text { Saraiva }\end{array}$ & $\begin{array}{c}\text { Professor } \\
\text { titular de } \\
\text { direito } \\
\text { constitucional } \\
\text { na Faculdade } \\
\text { de Direito da } \\
\text { USP }\end{array}$ & $\begin{array}{l}\text { Ministro da Justiça em caráter interino (1969-1971); Chefe } \\
\text { de Gabinete e Secretário-Geral do Ministério da Justiça. } \\
\text { Secretário de Administração do Estado de São Paulo (1972). } \\
\text { Secretário de Justiça do Estado de São Paulo (1972-1973). } \\
\text { Diretor da Faculdade de Direito da USP (1973-1974). } \\
\text { Vice-Governador do Estado de São Paulo (1975-1979). } \\
\text { Assessor do Ministro da Justiça Alfredo Buzaid durante o } \\
\text { governo Emílio Garrastazu Médici. } \\
\text { Integrou o Conselho Federal de Educação (1983-1994), do } \\
\text { qual foi Vice-Presidente e depois Presidente (1991-1994), } \\
\text { e foi membro do Conselho Estadual de Educação de São } \\
\text { Paulo (1981-1983). } \\
\text { Membro do Conselho Federal de Educação, do Conselho de } \\
\text { Orientação Jurídica da Federação e do Centro das Indústrias } \\
\text { do Estado de São Paulo e chefe do Departamento de Direito } \\
\text { do Estado da Faculdade de Direito da USP. }\end{array}$ \\
\hline
\end{tabular}

Fonte: Plataforma Lattes (consultada em 14 mar. 2012) e site da Associação Internacional de Direito e Economia (AIDE). Base de dados do projeto de pesquisa Intérpretes da Constituição, porta-vozes de políticas: juristas e ordem política brasileira (1990-2010).

A esse conjunto de proposições sobre a interpretação da Constituição, que tem como centro a tese da "ingovernabilidade" e da "(in)efetividade" de normas "sociais", se vinculam também Celso Ribeiro Bastos, Ives Gandra da Silva Martins e Ney Prado, que conformam um polo "conservador" nesse conjunto de tomadas de posição. No outro polo há um grupo "renovador", formado por autores que defendem a "plena aplicabilidade das normas do texto de 1988" e a "redemocratização do Estado", em que se destacam Dalmo de Abreu Dallari, Paulo Bonavides e José Afonso da Silva.

Também aparece nesse polo a defesa do ativismo político em torno da interpretação "social" da Constituição, posicionamento que influenciará grande número de doutrinadores 
ao longo da década de 2000, sustentando intelectualmente o protagonismo dos tribunais na esfera da execução de políticas públicas (cf. Engelmann e Cunha Filho, 2013). Do segmento "renovador", Dalmo de Abreu Dallari se destaca; professor catedrático do curso de direito da Universidade de São Paulo, é autor do manual de teoria do Estado de maior repercussão na área jurídica: Elementos de teoria geral do Estado. A obra, produzida em 1971, foi reeditada mais de trinta vezes até 2012. Nela, o jurista se posiciona sobre o perfil que pode assumir a produção de "conhecimento sobre o Estado", argumentando tratar-se de um saber que "deve voltar-se para a preservação e promoção dos direitos fundamentais da pessoa humana" (Dallari, 2009). Nesse polo, também aparece Paulo Bonavides - autor do Curso de direito constitucional. Sua trajetória intelectual contempla o investimento na "cientificização" da doutrina, explícita em seu Curso de direito constitucional, cuja primeira edição é de 1982. Bonavides difundiu no Brasil a defesa da "teoria material da Constituição", fundada no "dissídio entre os constitucionalistas europeus" e centrada na oposição entre os "positivistas formalistas" e os adeptos do "antiformalismo" do direito constitucional contemporâneo, que tem por pressuposto a "crítica" ao modelo de Estado liberal (Bonavides, 2001, p. 77).

Neste caso, se trata de um jurista dotado de forte perfil acadêmico. Seu manual reflete a importação do debate político europeu do século XIX, que repercute após as duas guerras mundiais, opondo a "socialdemocracia" e o "liberalismo", que, na Europa, foi traduzido para o direito constitucional como oposição entre "teoria formal" (liberalismo político) e "teoria material" da Constituição (socialdemocracia). Nossa última Constituição, por ser mais "material" do que "formal", ou seja, por ter sua legitimidade jurídica fundada no conteúdo de suas normas e princípios e não apenas em seus aspectos formais, seria 
plenamente aplicável pelos magistrados diante das diversas demandas originárias das camadas desfavorecidas da sociedade. A doutrina de Paulo Bonavides em seu Curso de direito constitucional é anterior ao processo constituinte de 1987-88; sua obra obterá maior repercussão a partir do momento da Constituinte.

Mesmo antes da promulgação da Constituição, já se pode encontrar os investimentos no debate em torno de modelos constitucionais, como exemplifica o caso de Ferreira Filho, com a publicação de A democracia possivel, de 1972, obra que atingiu a quinta edição em 1979; A reconstrução da democracia, de 1979, e Ideias para a nova Constituição brasileira, de 1987. Nessas obras, Manoel Gonçalves Ferreira Filho se posicionava no debate do modelo constitucional que deveria ser adotado no Brasil, situando a discussão em termos de uma oposição entre "modelo ideal" e "modelo possível" de Constituição. Desse modo, o constitucionalis190 ta criticava os "utopistas" pela defesa de uma "Constituição transformadora" da realidade social, alegando que:

[...] esta virtualidade transformadora é limitada pela própria realidade que ela pretende alterar. Se muito grande é o descompasso entre os padrões que pretende e os que a comunidade pratica, muito provavelmente suas prescrições permanecerão letra morta. Ou, como se diz no jargão jurídico, não terão efetividade, ou eficácia (Ferreira Filho, 1987, p. 35).

O sentido de Constituição expresso por Paulo Bonavides contrapõe-se, assim, à posição assumida por Manoel Gonçalves Ferreira Filho, pois este adere a uma visão contrária ao constitucionalismo social, com base na experiência do constitucionalismo português e espanhol da década de 1970. Ferreira Filho (1994, p. 221) considera a forma "muito extensa", "idealizada" e inviável nas condições brasileiras, 
portanto, "irrealista”, e "inaplicável”, sobrecarregando o Estado de demandas que não tem como atender. Os manuais dos autores críticos do modelo político do texto de 1988 continuaram sendo reeditados após a promulgação da Constituição, convivendo com as repercussões políticas da diversificação da produção doutrinária ligada aos variados usos da noção do conhecimento constitucional como "ferramenta de transformação social”.

A análise comparada dos trajetos profissionais, acadêmicos e políticos, assim como dos títulos honoríficos e da inserção em associações presente na biografia dos autores fornece indicações sobre a imbricação do debate das doutrinas de direito constitucional com o espaço do poder político, as quais merecem ser aprofundadas em estudos futuros. Essa proximidade que posiciona a disciplina de direito constitucional como formuladora de sentidos para as noções de Estado e das instituições também é equivalente à própria inserção dos autores nas diferentes esferas do poder. Nitidamente, na geração de constitucionalistas cuja produção repercute mais na década de 1990, há grande proximidade com o espaço da representação política, sendo Manoel Gonçalves Ferreira Filho o autor mais destacado nesse quesito, uma vez que ocuparia diversos postos públicos, entre eles os de secretário de Estado, vice-governador e ministro. Outra modalidade de capital político pode ser encontrada na atividade de consultoria, participação constante em comissões legislativas e associações das mais diversas espécies, combinada com a ostentação de um grande número de títulos, comendas e distinções acadêmicas.

Interessa notar que autores com maior capital político indicado pela sucessiva ocupação de postos públicos tendem a reivindicar menos a cientificidade de seu trabalho. Diferentemente, autores que tem sua legitimidade política derivada principalmente da sua posição como "catedrático”, tais como Paulo Bonavides e Ives Gandra da Silva 
Martins, investem mais no debate acadêmico e científico. Em um agrupamento, trata-se de maior proximidade com o espaço da política representativa pela ocupação de postos e mesmo da produção de comentários sobre textos de leis, ou seja, na busca mais nítida da certificação jurídica do jogo político. No outro, predomina maior investimento na erudição, na linguagem hermética do direito que se soma à presença em organizações mais periféricas em relação ao poder político, como as associações de juristas, abordadas a seguir.

\section{Em torno do sentido político da regra: as associações de constitucionalistas}

Em 1979 foi fundada em São Paulo a associação de constitucionalistas denominada Instituto Brasileiro de Direito Constitucional (IBDC). No site do Instituto aparece a justificativa de promover o desenvolvimento científico do direito consti-

192 tucional num período de "turbulências políticas".

Na década de 70, em meio às turbulências políticas que o Brasil atravessava, alguns professores de Direito Constitucional vinham promovendo o estudo aprofundado e a pesquisa desse ramo da Ciência Jurídica. Logo vislumbraram a necessidade de criar-se uma entidade que passasse a reunir os constitucionalistas de todo o País, entendidos estes como todos aqueles que tivessem militância no magistério do Direito Constitucional ou que se dedicassem à sua pesquisa.

Com esse animus, em 20 de fevereiro de 1979, os professores Celso Ribeiro Bastos, Paulo Bonavides, Michel Temer, Aricê Moacyr do Amaral Santos, Antonio Carlos Mendes, Luciano Francisco Pacheco do Amaral Junior, Cleômenes Mário Dias Baptista, José Geraldo Ataliba Nogueira, Péricles Prade e Francisco Antonio Lima Cavalcanti reuniram-se para constituir uma associação civil sem fins lucrativos, 
políticos ou religiosos à qual denominaram IBDC - Instituto Brasileiro de Direito Constitucional ${ }^{7}$.

Entre os fundadores dessa entidade estão presentes nomes de um extrato relevante de juristas e políticos, autores de manuais de doutrina constitucional sucessivamente reeditados, como Celso Ribeiro Bastos, Michel Temer e Paulo Bonavides. O IBDC publica uma revista de doutrina constitucional de abrangência nacional, antes Cadernos de Direito Constitucional e Ciência Política, depois denominada Revista de Direito Constitucional e Internacional, difundida pela editora Revista dos Tribunais, especializada em publicações jurídicas.

A Associação Internacional de Direito e Economia (AIDE) foi fundada em 1987 por Ives Gandra da Silva Martins, Carlos Alberto Longo, Celso Ribeiro Bastos e Celso Luiz Martone. A AIDE possui uma composição diversificada, englobando cientistas sociais, advogados, economistas e políticos. No seu quadro de associados figuram nomes com inserção política destacada, como Antônio Delfim Netto, Pedro Malan, Fernando Henrique Cardoso, Celso Lafer, Mário Henrique Simonsen e José Serra ${ }^{8}$. Desde 1988, a AIDE promoveu 29 eventos (cursos, seminários, fóruns, congressos) tratando de temas ligados ao debate constitucional "focados no Estado", no "papel do Ministério Público" e na problemática da "intervenção do Estado no mercado". O principal eixo dessa associação é o investimento na difusão de doutrinas sustentadas na aproximação das teorias e práticas do campo jurídico com o espaço da economia.

Em contraste com a AIDE, temos no período mais recente, após uma década da promulgação da Constituição, a criação da Associação Brasileira de Constitucionalistas

\footnotetext{
${ }^{7}$ Disponível em: <http://www.ibdc.com.br/home/quemsomos.htm>. Acesso em: 2 jun. 2013.

${ }^{8}$ Dados disponíveis em: <http://www.aide.org.br/academicos.html>. Acesso em: 30 maio 2012.
} 
Democratas (ABCD). Fundada em 2000, por José Afonso da Silva, e sediada em São Paulo, seu surgimento indica que a polarização no espaço doutrinário, visível durante o processo constituinte, permaneceu vigente entre os constitucionalistas. No manifesto de criação, a Carta de Princípios, dessa Associação fica evidenciada a tomada de posição a favor do ativismo constitucional voltado para a efetivação de direitos sociais ${ }^{9}$.

Os constitucionalistas democratas resolvem fundar uma instituição destinada a congregá-los no fim comum de defesa da Constituição e do Estado Democrático de Direito, defesa não da Constituição como um simples nome, mas da Constituição como repositório de valores políticos populares, que dão essência aos princípios democráticos. A democracia que defendem é a democracia concebida como revolução permanente que tem no povo a sua primeira e fundamental referência, daí por que postulam pela vigência, eficácia e aplicabilidade dos direitos sociais e, em consequência, por uma ideologia da igualdade, sem o que os direitos individuais também carecerão de meios eficazes de sustentação para a maioria do povo ${ }^{10}$.

Dessa forma, a extensão do espaço doutrinário repercute os contrapontos que distinguem os constitucionalistas desde a Constituinte, contribuindo para as transformações

\footnotetext{
${ }^{9}$ Dentre os membros da ABCD há nomes de constitucionalistas destacados em várias regiões, como Siqueira Castro (RJ), Clèmerson Merlin Clève (PR), Dalmo De Abreu Dallari (SP), Eros Roberto Grau (SP), Flávia Piovesan (SP), Ingo Wolfgang Sarlet (RS), Ivo Dantas (PE), José Afonso da Silva (SP), José Ribas Vieira (RJ), Juarez Freitas (RS), Luís Afonso Heck (RS), Luís Roberto Barroso (RJ), Luis Virgílio Afonso Da Silva (SP), Miguel Reale Júnior (SP), Oscar Vilhena Vieira (SP), Paulo Bonavides (CE), Paulo Lopo Saraiva (RN), Walter Ceneviva (SP), Willis Santiago Guerra Filho (SP). A lista completa encontra-se disponível em: <http:// www.constitucionalistas.com.br/associados/>. Acesso em: 30 maio 2012.

${ }^{10}$ Conforme http://www.constitucionalistas.com.br/carta/>. Acesso em: 30 maio 2012.
} 
do campo jurídico brasileiro nas décadas de 1990 e 2000. Em larga medida, se pode mensurar o seu papel na expansão do constitucionalismo e relacioná-los com a emergência de uma nova geração de autores.

\section{Neoconstitucionalismo e novos experts}

A partir da década de 1990, repercutindo um quadro de expansão da pós-graduação e das revistas de direito, diversifica-se a produção de doutrinas constitucionais no Brasil. Identificam-se dois eixos principais por onde se dá a difusão. Um lado vai na direção do discurso fundado na jurisprudência, sobretudo emitida pelo Supremo Tribunal Federal; outro, baseia-se na filosofia política contemporânea, em doutrinas elaboradas por autores estrangeiros como Ronald Dworkin e Robert Alexy, vinculados à matriz teórica anglo-saxônica.

O neoconstitucionalismo aparece como uma atualização do direito constitucional, operacionalizada pelo redescobrimento do "valor da doutrina". Essa tendência vincula-se à demanda por "especialistas" em interpretação afinada com a internacionalização do rule of law (Dezalay e Garth, 2002) e pela conjuntura interna favorável à expansão do mercado de serviços jurídicos. A mobilização do espaço judicial por grupos sociais, associações, sindicatos, defensorias públicas, instituições como o Ministério Público e por indivíduos buscando "prestações positivas" do Estado por via judicial amplia a presença do Judiciário e de seus agentes na definição de políticas públicas. No mesmo cenário, a "judicialização" do processo político, com a proliferação de ações de inconstitucionalidade, ações de improbidade e responsabilidade fiscal contra administradores públicos e o ativismo normativo sobre o processo eleitoral, por exemplo, exige novas formulações científicas sobre a maneira jurídica de equacionar os embates políticos. Além dessas questões mais afeitas ao 
ativismo em torno do espaço judicial, a crescente internacionalização de modelos institucionais atrelada à globalização das relações econômicas repercute fortemente na interpretação constitucional.

Nessa perspectiva, conforme aponta Delmas (2011, p. 6), as relações entre a expertise científica e a ação política vêm se tornando objeto de estudos que atraem cada vez mais o interesse sociológico pelo fato de a mobilização dos saberes para a ação ter se desenvolvido e se diversificado. A autora associa o fenômeno da ampliação da mobilização da expertise técnica nas decisões políticas ao "nascimento de um sistema normativo neoliberal". Ela enfatiza como exemplo "a propagação de moldes da literatura econômica às políticas para a formulação de uma 'nova gestão pública' motivou diversas e vastas reformas administrativas em muitos países ocidentais" (Delmas, 2011, p. 71).

No caso do constitucionalismo brasileiro, em que a 196 vertente "social" que reivindica a "prestação positiva" do Estado torna-se predominante, também se verifica que o investimento em temas econômicos liga-se à (re)invenção da área, repercutindo na produção dos constitucionalistas. Assim, da noção de "ordem econômica", desenvolve-se o subcampo do direito constitucional econômico. Manuais e artigos de direito constitucional econômico se multiplicam a partir de 1990, reunindo constitucionalistas de várias gerações e alinhamentos ideológicos, alcançando sucessivas reedições na década de 2000. Isso exemplifica a repercussão no Brasil da combinação entre a difusão internacional de expertises sobre interpretação constitucional com uma visão econômica, que afetou a produção de saberes sobre o Estado. O resultado é uma doutrina constitucional voltada a temas, administrativos e tributários, e à eficiência do Estado, como ilustram trabalhos mais recentes de José Afonso da Silva (2002), Ives Gandra da Silva Martins (2012), Luis Roberto Barroso (2002), 
Eros Roberto Grau (2007), Celso Ribeiro Bastos (2003), André Ramos Tavares (2003), Gilberto Bercovici (2005) e Luis Alberto David Araujo e Vidal Serrano Nunes Júnior (2009).

Seguindo a onda de ascensão do constitucionalismo, os autores brasileiros continuarão investindo na "cruzada de modernização" da doutrina jurídica. Essa atualização aparece no quadro de um fenômeno apontado por Dezalay e Garth (2002) como investimento na "cientificização" da linguagem jurídica, de modo a legitimar a transformação do perfil das instituições estatais, tanto nos Estados Unidos como na América Latina. Os temas do neoconstitucionalismo penetram no espaço doutrinário por vários canais, vinculando-se à tríade "Constituição-Economia-Direitos fundamentais”. As principais editoras contribuem para fomentar o expressivo investimento de novos autores na produção e obras coletivas de teor laudatório ${ }^{11}$. Coexistindo com as obras gerais florescem publicações que tratam do aperfeiçoamento do processo constitucional, uso das "novas tecnologias de informação e comunicação pelas cortes judiciárias", as "novas técnicas de controle de constitucionalidade", e sobre o "papel do Poder Judiciário", com destaque para o Supremo Tribunal Federal na interpretação das leis e da Constituição.

Além do crescimento da adesão dos juristas à agenda teórica e política norte-americana, o estímulo para a produção de artigos científicos é maior a partir desse período, com a proliferação de espaços para publicação de trabalhos acadêmicos. A legitimação da atuação judicial, em prol da

\footnotetext{
${ }^{11}$ Destacam-se dentre as obras de homenagem à "grandes constitucionalistas": Direito constitucional: estudos em homenagem a Paulo Bonavides (Malheiros ed., 2001), conjugando a participação de mais de vinte doutrinadores; Estudos de direito constitucional em homenagem a José Afonso da Silva (Malheiros ed., 2003); e ainda Lições de direito constitucional em homenagem ao jurista Celso Bastos (Saraiva, 2005), de André Ramos Tavares, Ives Gandra da Silva Martins e Antônio Carlos Mendes. Para mais detalhes, ver Penna (2011).
} 
"tutela dos direitos humanos" e os "direitos fundamentais" são temáticas recorrentes nos debates no seio do neoconstitucionalismo.

\section{Os constitucionalistas e a pesquisa acadêmica}

Indicativo mais forte da diversificação das doutrinas constitucionais, um primeiro mapa geral dos temas presentes no espaço acadêmico pode ser obtido com a análise dos perfis da produção dos docentes de pós-graduação. A diferenciação entre pesquisadores na pós-graduação stricto sensu em relação aos professores de graduação é importante para captar a grande diversidade de temas que afloram nesse espaço que acompanha a complexificação das batalhas de sentido das regras constitucionais nos tribunais. Também a análise permite estabelecer elementos para a compreensão do perfil dos produtos resultantes da grande expansão da condição de professor de pós-graduação entre os juristas 198 que tem lugar no Brasil a partir da década de 1990, constituindo um novo segmento da elite jurídica (cf. Engelmann, 2008, 2012).

Para obter um mapa e o perfil da produção acadêmica, utilizou-se o diretório dos grupos de pesquisa registrados no CNPq através da busca dos docentes cadastrados com o tema "direito constitucional". Por esse mecanismo, se chegou a 127 grupos registrados majoritariamente desde 2005. Desse universo foram selecionados 70 grupos, por meio de análise qualitativa, cujos temas estavam menos dispersos em relação à disciplina nas suas linhas de pesquisa.

A dispersão de temas entre os grupos é bastante significativa, podendo-se observar divisões entre a concentração em assuntos mais genéricos entre docentes de universidades tradicionais contraposta à grande diversidade de temas específicos em universidades de trajetória mais recente (ver Tabela 1). 
Tabela 1

Frequência e porcentagem de temas e linhas de pesquisa

\begin{tabular}{|c|c|c|}
\hline Tema & Frequência & $\%$ \\
\hline Jurisdição constitucional & 20 & 24,3 \\
\hline Estado e sistema de justiça, acesso à justiça & 14 & 17,0 \\
\hline Constitucionalização do direito privado & 10 & 12,1 \\
\hline Interpretação/hermenêutica constitucional & 7 & 8,5 \\
\hline Direito constitucional & 6 & 7,3 \\
\hline Direito constitucional e internacionalização & 5 & 6,0 \\
\hline Decisões judiciais & 3 & 3,6 \\
\hline Direito constitucional ambiental & 3 & 3,6 \\
\hline Direito e setor regulatório & 3 & 3,6 \\
\hline História constitucional e direito constitucional comparado & 3 & 3,6 \\
\hline Direito constitucional e povos indígenas e relações raciais & 3 & 3,6 \\
\hline Educação e direitos humanos & 3 & 3,6 \\
\hline Direito constitucional e propriedade intelectual & 1 & 1,2 \\
\hline Direitos sociais & 1 & 1,2 \\
\hline Total & 82 & 99,9 \\
\hline
\end{tabular}

Fonte: Plataforma Lattes (consultada em janeiro de 2013). Base de dados do projeto de pesquisa Intérpretes da Constituição, porta-vozes de políticas: juristas e ordem política brasileira (1990-2010).

Verifica-se que temas vinculados ao processo constitucional, relacionados diretamente com as demandas presentes nas cortes, aparecem com maior frequência entre os pesquisadores. A "jurisdição constitucional” e temas que pautam o sistema e o "acesso à justiça" se destacam comparativamente à "história constitucional", por exemplo, tema mais afeito ao espaço acadêmico sem repercussão imediata entre os praticantes do direito.

A grande proliferação de revistas acadêmicas também é um fenômeno mais perceptível nas últimas décadas e acompanha a expansão dos cursos de pós-graduação. Em 
alguma medida, tais publicações servem como espaço para veicular a produção centrada nas doutrinas jurídicas enquanto conhecimento "científico" - contrapondo-se aos manuais mais consagrados -, com ampla circulação no ensino universitário de graduação e em preparatórios para concursos públicos. Entretanto, uma análise mais detida mostra que a relação entre a importância acadêmica do periódico, estabelecida por critérios estritos, não corresponde à sua difusão e legitimidade entre os produtores de doutrinas, muito menos entre os práticos do direito. Nesse sentido, pode-se contrapor o prestígio da classificação “qualis Capes” para periódicos, definido por critérios acadêmicos pautados por pesquisadores posicionados na pós-graduação, ao prestígio de editoras de revistas, com ampla repercussão no campo jurídico.

Crescentemente no Brasil, um dos indicadores de institucionalização do sistema de pós-graduação e prestígio na car200 reira acadêmica é o volume de publicações em revistas com melhor avaliação nas respectivas áreas de conhecimento. No caso do campo dos professores de direito, esse índice de publicação envolve uma concorrência mais forte entre as que possuem prestígio perante o universo dos práticos. Representativas dessas revistas com maior penetração entre operadores do direito são as publicações vinculadas a tribunais e associações. Nota-se que, mais recentemente, essas revistas de maior repercussão têm buscado se adaptar às regras do sistema "qualis Capes", criado para hierarquizar os periódicos.

O mapeamento das revistas onde publicam os líderes dos grupos de pesquisa registrados no $\mathrm{CNPq}$ revela indicações interessantes sobre a legitimidade acadêmica dos periódicos. Totalizando-se a produção veiculada pelos líderes, chega-se a 810 publicações distribuídas em 222 periódicos. Entre as que concentram maior número de artigos estão as revistas com menor índice qualis. $\mathrm{Na}$ 
Tabela 2 são destacadas as dez revistas que aparecem com maior frequência.

Também é importante observar a grande dispersão de publicações. As revistas que concentram maior frequência compõem apenas $30 \%$, a mais bem classificada no qualis Capes possui conceito B1. Considerando-se que se está analisando as publicações de pesquisadores com doutorado em direito e majoritariamente ancorados em programas de pós-graduação, é interessante verificar que o destaque esteja em revistas que se concentram no nível C e B, não aparecendo nenhuma revista com qualis $\mathrm{A}$.

Uma das hipóteses que se pode extrair desses dados é que o sistema de avaliação de revistas proposto pelo modelo qualis Capes ainda tem pouca legitimidade no meio docente dos cursos de direito. Também parece haver um reforço da nossa hipótese inicial de que a produção intelectual no âmbito jurídico, mesmo ancorada no sistema de pós-graduação, é estreitamente condicionada pelo espaço das práticas jurídicas. Nesse sentido, a importância do consumo desses bens simbólicos entre praticantes do direito, alavancada por editoras comerciais especializadas na área, é mais forte do que a certificação acadêmica que confere legitimidade no mundo científico para os periódicos.

O grande desafio para o estudo da formação do pensamento político construído nas formas jurídicas é justamente identificar, na mobilização da técnica mais apurada, os conteúdos que indicam oposições baseadas em batalhas políticas que almejam todo o tempo apresentar-se como um "debate científico". Em se tratando das doutrinas constitucionais, assim como em qualquer caso de debate em que entra em jogo diretamente o sentido "correto" do Estado ou de suas instituições de governo, essa vigilância 


\section{Tabela 2}

Dez revistas com maior frequência de artigos de líderes de grupos de pesquisa

\begin{tabular}{|c|c|c|c|c|}
\hline Revistas & Editora & Freq. & Qualis & $\%$ \\
\hline Diritto \& Diritti & Diritto. It (Itália) & 40 & C & 5,00 \\
\hline Evocati revista & Editora Evocati (SE) & 40 & C & 5,00 \\
\hline $\begin{array}{l}\text { Revista de Direito Constitucional } \\
\text { e Internacional (nome anterior: } \\
\text { Cadernos de Direito Constitucional } \\
\text { e Ciência Política) }\end{array}$ & $\begin{array}{l}\text { IBDC*/Ed. Revista dos } \\
\text { Tribunais (SP) }\end{array}$ & 39 & B2 & 4,875 \\
\hline Revista de Processo & $\begin{array}{c}\text { IBDP }^{* *} / \text { Ed. Revista dos } \\
\text { Tribunais (SP) }\end{array}$ & 37 & B1 & 4,625 \\
\hline Revista Forense & Editora Forense (RJ) & 25 & B3 & 3,125 \\
\hline $\begin{array}{c}\text { Revista Brasileira de Direito } \\
\text { Constitucional }\end{array}$ & ESDC*** & 24 & C & 3,00 \\
\hline Revista da Ajuris & AJURIS**** (RS) & 16 & B2 & 2,00 \\
\hline Fórum Administrativo & Editora Fórum (MG) & 15 & B4 & 1,875 \\
\hline Interesse Público & Editora Fórum (MG) & 12 & B4 & 1,50 \\
\hline Revista Dialética de Direito Tributário & Editora Dialética (SP) & 12 & C & 1,50 \\
\hline Demais publicações & & 540 & & 67,50 \\
\hline Total p/frequência & & 800 & & 100 \\
\hline
\end{tabular}

*IBDC (Instituto Brasileiro de Direito Constitucional)

**IBDP (Instituto Brasileiro de Direito Processual)

***ESDC (Escola Superior de Direito Constitucional)

****AJURIS (Associação dos Juízes do Rio Grande do Sul)

Fontes: Web Qualis Capes (consultado em junho de 2013). Base de dados do projeto de pesquisa Intérpretes da Constituição, porta-vozes de políticas: juristas e ordem política brasileira (1990-2010). 
precisa ser mais forte. Neste caso, o pressuposto da legitimidade pública dos enunciadores tem por princípio a denegação da natureza política dos conteúdos dos argumentos mobilizados. Assim, as oposições acerca da interpretação "correta" da Constituição, que a apresentam como um entrave ao "desenvolvimento econômico" ou como a "promotora da cidadania", ou ainda, a guardiã dos diversos "novos direitos" precisam ser lidas no contexto das lutas conjunturais que permearam a redemocratização do país.

A importância dos juristas-constitucionalistas no debate político e da expansão da produção de doutrinas torna-se mais complexa quando deixa de ser realizada apenas por grandes personalidades afeitas à produção de manuais centrados em questões genéricas de "teoria do Estado". A complexificação das demandas exige a diversificação dos produtores de sentido. Logo, a análise do polo mais acadêmico dos constitucionalistas "pesquisadores" precisa ser considerada em conjunto com as grandes personalidades do direito para a compreensão da divisão do trabalho e das lógicas presentes na produção da "crença na racionalidade das normas” em diferentes contextos e conjunturas.

Cada vez mais, temas específicos são "postos na forma jurídica" para subsidiar as respostas das instituições judiciais a demandas políticas ou tornar decisões políticas juridicamente válidas. Pode-se afirmar que a mobilização do espaço judicial em torno de causas sociais e a crescente internacionalização de modelos de instituições, alimenta a expansão disciplinar do direito constitucional. Nesse cenário, as doutrinas, enquanto bens simbólicos, e os constitucionalistas, enquanto intérpretes autorizados da forma jurídica da política, ganham projeção como portadores do rule of law e de uma visão moral da atividade política que merece ser mais bem estudada. 


\section{Fabiano Engelmann}

é professor de graduação e pós-graduação do Departamento de Ciência Política da UFRGS e bolsista de Produtividade do CNPq.

\section{Luciana Penna}

é doutoranda em Ciência Política pela UFRGS e bolsista da Capes.

\section{Bibliografia}

ADORNO, S. 1988. Os aprendizes do poder. Rio de Janeiro: Paz e Terra. ARAUJO, L. A. D.; NUNES JÚNIOR, V. S. 2009. Curso de direito constitucional. 13. ed. São Paulo: Saraiva.

BARROSO, L. R. 2002. "A ordem econômica constitucional e os limites à atuação estatal no controle de preços”. Revista Diálogo Jurídico, Salvador (BA), n. 14, jun.-ago.

BASTOS, C. R. 1996. Curso de direito constitucional. 17. ed. São Paulo: Saraiva.

204 2003. Curso de direito econômico. São Paulo: Celso Bastos Ed.

BERCOVICI, G. 2005. Constituição econômica e desenvolvimento: uma leitura a partir da Constituição de 1988. São Paulo: Malheiros Ed.

BONAVIDES, P. 2001. Curso de direito constitucional. 11. ed. São Paulo:

Malheiros Ed.

BOURDIEU, P. 1986. "La force du droit: eléments pour une sociologie du champ juridique". Actes de la Recherche en Sciences Sociales, n. 64, sept.

CARVALHO, J. M. 1996. A construção da ordem: a elite política imperial. 2. ed. Rio de Janeiro: Ed. UFRJ.

CHEVALIER, J. 1993. "Les interprètes du droit”. In: POIRMEUR, Y.; BERNARD, A. La Doctrine Juridique. Paris: PUF.

CITTADINO, G. 2000. Pluralismo, direito e justiça distributiva: elementos da filosofia constitucional contemporânea. 2. ed. Rio de Janeiro: Lumen Juris.

DALLARI, D. A. 2009. Elementos de teoria geral do Estado. São Paulo: Saraiva. DELMAS, C. 2011. Sociologie politique de l'expertise. Paris: La Découvert.

DEZALAY, Yves. 1989. "La production doctrinale comme objet et terrain de luttes politiques et professionnelles”. In: BERNARD, A.; POIRMEUR, Y. La Doctrine Juridique. Paris: PUF.

DEZALAY, Y.; GARTH, B. 2002. The internationalization of palace wars: lawyers, economists and the contest to transform Latin American States. Chicago: University of Chicago. 
ENGELMANN, F. 2006a. "Internacionalização e ativismo judicial: as causas coletivas". Lua Nova [on-line], n. 69. . 2006b. Sociologia do campo jurídico: juristas e usos do direito. Porto Alegre: Safe.

. 2008. "Estudos no exterior e mediação de modelos institucionais: o caso dos juristas brasileiros”. Revista de Sociologia e Política, v. 16, pp. 145-57.

. 2012. "Globalização e poder de Estado: circulação internacional de elites e hierarquias do campo jurídico brasileiro”. Dados, Rio de Janeiro, v. 55, pp. 97-125.

ENGELMANN, F.; CUNHA FILHO, M. C. 2013. "Ações judiciais, conteúdos políticos: uma proposta de análise para o caso brasileiro”. Revista de Sociologia e Política, v. 21, n. 45, mar.

FERREIRA FILHO, M. G. 1987. Ideias para a nova Constituição brasileira. São Paulo: Saraiva. 1994. "Constituição e governabilidade". Revista de Informação Legislativa, Brasília, v. 31, n. 123, pp. 219-27 jul./set. 1995. Constituição e governabilidade: ensaio sobre a (in) governabilidade brasileira. São Paulo: Saraiva. . 2005a. Curso de direito constitucional. 31. ed. São Paulo: Saraiva. . 2005b. "A Constituição de 1988 - um balanço após dezesseis anos de vigência”. Revista Direito Público, v. 1, n. 8, abr./maio/jun. Disponível em: <http:/ /www.direitopublico.idp.edu.br/index.php/ direitopublico/article/view/449>. Acesso em: 27 set. 2011.

FERREIRA FILHO, M. G. "Judiciário está maduro para usar poder político". Entrevista concedida à Conjur. Disponível em: <http://www.conjur.com. br/2009-mai-03/entrevista-manoel-goncalves-ferreira-filho-advogado>. Acesso em: 14 mar. 2012.

GRAU, E. R. 2007. A ordem econômica na Constituição de 1988. 12. ed. São Paulo: Malheiros Ed.

GRAU, E. R.; CUNHA, S. S. da (orgs.). 2003. Estudos de direito constitucional em homenagem a José Afonso da Silva. São Paulo: Malheiros Ed.

GRAU, E. R.; GUERRA FILHO, W. S. (orgs.). 2001. Direito constitucional: estudos em homenagem a Paulo Bonavides. São Paulo: Malheiros Ed.

KOERNER, A. 1998. Judiciário e cidadania na Constituição da república brasileira. São Paulo: Hucitec/Edusp.

LACROIX, B. 1992. "Le politiste et l'usage des institutions: comment parler de la présidence de la République”. In: LACROIX, B.; LAGROYE, J. (dir.). Le président de la république: usages et genèses d'une institutions. Paris: Presses de la Fondation Nationale de Sciences Po. 
MARTINS, I. G. da S. 2012. "Contribuinte tinha mais segurança jurídica na ditadura”. Revista Consultor Jurídico, 11 nov. Disponível em: <http:/ / conjur.com.br>. Acesso em: 9 jul. 2013.

PENNA, L. E. 2011. "Sociologia política da doutrina jurídica: um caso representativo do pensamento constitucional brasileiro”. In: IV SEMINÁRIO NACIONAL DE CIÊNCIA POLÍTICA DA UFRGS, 2011. Porto Alegre.

POIRMEUR, Y. 1993. "Themes et debats autor du constitutionnalisme”. In: CHEVALIER, J. (org.). Droit et politique. Paris: PUF. pp. 13-39.

SACRISTE, G. 2011. La republique des constitutionalistes: professeurs de droit et légitimation de l'État en France (1870-1914). Paris: Presses de Sciences Po.

SARLET, I. W.; TIMM, L. B. (orgs.) 2008. Direitos fundamentais: orçamento e "reserva do possível". Porto Alegre: Livraria do Advogado Ed.

SARMENTO, Daniel (Coord.). Filosofia e Teoria Constitucional Contemporânea. Rio de Janeiro: Lúmen Júris, 2009.

SILVA, J. A. da. 1999. Curso de direito constitucional positivo. 16. ed. São Paulo: Malheiros Ed. 2002. "Garantias econômicas, políticas e jurídicas da eficácia dos direitos sociais". Mundo Jurídico. Disponível em: <www.mundojuridico. adv.br>. Acesso em: 9 jul. 2013. . 2008. Aplicabilidade das normas constitucionais. 7. ed. São Paulo: Malheiros Ed.

TAVARES, A. R. 2003. Direito constitucional econômico. São Paulo: Ed. Método.

TAVARES, A. R.; MARTINS, I. G. da S.; MENDES, A. C. 2005. Lições de direito constitucional em homenagem ao jurista Celso Bastos. São Paulo: Saraiva.

TROPER, M. 1993. "Le constitutionnalisme entre droit et politique". In: CHEVALIER, J. Droit et politique. Paris: PUF. pp. 82-94.

VENÂNCIO FILHO, A. 1977. Das arcadas ao bacharelismo: 150 anos de ensino jurídico no Brasil. São Paulo: Perspectiva. 


\title{
POLÍTICA NA FORMA DA LEI: O ESPAÇO DOS CONSTITUCIONALISTAS NO BRASIL DEMOCRÁTICO
}

\author{
FABIANO ENGELMANN
}

\section{LUCIANA PENNA}

Resumo: A adoção de uma nova Constituição favoreceu a legitimidade de categorias de "intérpretes autorizados" sobre as regras de funcionamento da atividade política e estatal no Brasil. Nesse cenário, a análise do espaço de produção das doutrinas jurídicas e dos "constitucionalistas" traz pistas importantes sobre a normatização da política democrática. Através do mapeamento dos autores de manuais de direito constitucional, das articulações em torno de periódicos e associações e dos grupos de pesquisa, buscou-se, neste artigo, explorar as principais polarizações no debate em torno da "interpretação da Constituição" que perpassa as últimas décadas. Foram utilizadas como fontes, sites de associações, editoras e revistas especializadas, a produção bibliográfica e a base do diretório de grupos de pesquisa do CNPq. Uma das principais conclusões deste estudo é a necessidade de discutir a diversificação do imbricamento das causas políticas com a forma jurídica, observada na mise en forme crescente do processo político, do ativismo político e da definição jurídica de políticas públicas.

Palavras-chave: Juristas; Política; Democracia.

\section{POLITICS IN FORM OF THE LAW: THE CONSTITUTIONELISTS SPACE IN DEMOCRATIC BRAZIL}

Abstract: The adoption of a new Constitution favored the legitimacy of "authoritative interpreters" on the rules of functioning of the political activity and state's activities in Brazil. In this scenario, the analysis of the production of legal doctrines and "constitutionalists" provides important clues about the normalization of democratic politics. By mapping the authors of manuals of constitutional law, the joints around journals, associations and research groups is possible one 
exploration of major concepts in the debate around the "interpretation of the Constitution" that permeates the last decades. For this research are used as sources, associations, publishers and magazines specialized websites, bibliographic production and the basis of the research groups of the CNPq. A key finding of the study is the need to discuss the diversification of political causes with legal form, observed in the mise en forme growing of the political process and the juridical activism.

Keywords: Jurists; Polity; Democracy. 